\title{
Dietary flavonoids and respiratory diseases: a population-based multi-case-control study in Italian adults
}

\author{
Veronica Mattioli ${ }^{1}$, Maria Elisabetta Zanolin ${ }^{1}$, Lucia Cazzoletti ${ }^{1}$, Roberto Bono ${ }^{2}$, \\ Isa Cerveri ${ }^{3}$, Marcello Ferrari ${ }^{4}$, Pietro Pirina ${ }^{5}$ and Vanessa Garcia-Larsen ${ }^{6, *}$ \\ 'Unit of Epidemiology and Medical Statistics, Department of Diagnostics and Public Health, University of \\ Verona, Verona, Italy: ${ }^{2}$ Department of Public Health and Pediatrics, University of Turin, Turin, Italy: ${ }^{3}$ Division of \\ Respiratory Diseases, Istituto di Ricovero e Cura a Carattere Scientifico 'San Matteo' Hospital Foundation, \\ University of Pavia, Pavia, Italy: ${ }^{4}$ Unit of Respiratory Diseases, Department of Internal Medicine, University of \\ Verona, Verona, Italy: ${ }^{5}$ Institute of Respiratory Diseases, University of Sassari, Sassari, Italy: ${ }^{6}$ Program in Human \\ Nutrition, Department of International Health, Johns Hopkins Bloomberg School of Public Health, $615 \mathrm{~N}$. Wolfe Street, \\ Baltimore, MD 21205, USA
}

Submitted 14 June 2018: Final revision received 4 August 2019: Accepted 12 August 2019

\begin{abstract}
Objective: To analyse the associations between chronic respiratory diseases and intakes of total flavonoids and their major subclasses (flavanones, anthocyanins, flavan-3-ols, flavonols, flavones, polymers and proanthocyanidins).

Design: Multi-case-control study.

Setting: The analysis was conducted in the frame of the Genes Environment Interaction in Respiratory Diseases (GEIRD) study. The European Prospective Investigation into Cancer and Nutrition FFQ was used to ascertain dietary intake. Multinomial regression models adjusting for age, sex, centre, BMI, smoking habit, alcohol intake, education, total energy intake, vitamin $\mathrm{C}$ intake and total fruit intake were used to examine the associations between dietary exposures and the relative risk ratio (RRR) of being a case.

Participants: Individuals ( $n$ 990) hierarchically defined as follows: cases with asthma (current, $n 159$; past, $n 78$ ), chronic bronchitis ( $n 47)$, rhinitis (allergic rhinitis, $n$ 167; non-allergic rhinitis, $n 142$ ) and controls ( $n$ 97).

Results: An increase of $1 \mathrm{SD}$ in flavanones was associated with a reduced risk of non-allergic rhinitis (adjusted RRR $=0.68$, 95\% CI 0.47, 0.97); a similar result was found comparing the highest $v$. lowest quartile of flavanones intake (adjusted $\mathrm{RRR}=0 \cdot 24,95 \%$ CI $0 \cdot 10,0 \cdot 59$ ).

Conclusions: Flavonoids contained in fruits and vegetables, especially flavanones, might reduce the risk of non-allergic rhinitis. No associations were found between other flavonoids and the considered outcomes.
\end{abstract}

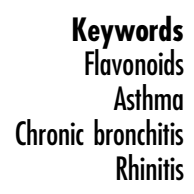

Chronic inflammation in the airways is a central feature in asthma and other respiratory diseases and is mostly driven by oxidative stress ${ }^{(1,2)}$. The imbalance between endogenous oxidant and antioxidant substances can be influenced by diet, in particular fruits and vegetables, which are rich in antioxidants. Epidemiological evidence suggests that a diet rich in these foods might have a beneficial effect on asthma and lung function in adults and children $^{(1,3-6)}$.

Extensive experimental evidence shows that flavonoids, which are polyphenols synthesized by plants, have antioxidant, anti-allergic and anti-inflammatory effects $^{(7-13)}$. It is known that flavonoids can reduce the activation of the cyclooxygenase gene, which is involved in the inflammatory response ${ }^{(14,15)}$, and they might act as an inhibitor of lipoxygenase, whose products are involved in the pathogenesis of a series of inflammatory diseases, including rhinitis ${ }^{(16)}$. Lipoxygenase uses peroxyl radical complexes for the metabolism of arachidonic acid and flavonoids might act as antioxidants by neutralizing the radicals ${ }^{(17)}$.

In spite of the extensive and promising experimental evidence suggesting a potential benefit of flavonoids on 
airways disease, epidemiological studies examining this association are still scant and limited to few flavonoid subclasses ${ }^{(18)}$. In Finnish adults, higher intakes of quercetin, naringenin and hesperetin were associated with a reduced risk of asthma ${ }^{(19)}$. In a case-control study conducted in London, dietary intake of three major flavonoids (catechins, flavonols and flavones) was not associated with asthma or chronic bronchitis ${ }^{(20)}$

GEIRD (Genes Environment Interaction in Respiratory Diseases), a population-based multi-case-control study, aimed to provide evidence on environmental exposures, history of disease, treatment, genetic information and measurements of markers of inflammation in individuals affected by asthma, allergic rhinitis and chronic obstructive pulmonary disease $(\mathrm{COPD})^{(21)}$. In this population, we investigated the association of dietary intake of six major classes of flavonoids and risk of asthma, chronic bronchitis and rhinitis.

\section{Materials and methods}

\section{Study design}

GEIRD, a population-based multi-case-control study, is a two-stage project which involves seven Italian centres ${ }^{(21)}$. The first stage aimed to find probable cases and controls through a screening questionnaire on respiratory symptoms. The questionnaire was mailed to pre-existing random cohorts (the Italian Study on Asthma in Young Adults (ISAYA) $^{(22)}$, the Italian arm of the European Community Respiratory Health Survey (ECRHS-Italy) ${ }^{(23)}$ ) and a new random sample from the general population (20-84 years of age, male/female $=1 / 1$ ). The second stage aimed to ascertain the respiratory condition of the individuals through a clinical visit. Individuals invited to clinics were a random sample of those who reported signs suggestive of rhinitis and those free from any respiratory symptoms, and all individuals who reported signs suggestive of chronic bronchitis (CB), COPD or asthma. In this stage, each individual underwent a computer-assisted clinical interview, lung function tests, reversibility test, methacholine test and skin prick test (SPT), and dietary information was collected through a self-administered FFQ. All measurement protocols agreed with international guidelines (www.geird.org) ${ }^{(21)}$. In the present analysis, only the individuals with information on the FFQ recruited in the years from 2007 to 2010 in the centres of Pavia, Torino, Sassari and Verona were considered.

\section{Lung function and allergological tests}

All outcome variables were assessed following standard procedures that included previously validated spirometric tests. Individuals underwent spirometry for forced expiratory volume in the first second $\left(\mathrm{FEV}_{1}\right)$ and forced vital capacity (FVC), measured according to the American Thoracic Society reproducibility criteria ${ }^{(24)} . \mathrm{FEV}_{1} \%$ predicted and the lower limit of normal (LLN) for the $\mathrm{FEV}_{1} / \mathrm{FEC}$ were calculated on the basis of Quanjer et al.'s equations ${ }^{(25)}$. Individuals with a $\mathrm{FEV}_{1} / \mathrm{FVC} \geq 70 \%$ and $\geq$ LLN underwent a methacholine challenge test, which followed a protocol described elsewhere ${ }^{(26)}$. Individuals with a $\mathrm{FEV}_{1} / \mathrm{FVC}<70 \%$ or $<$ LLN underwent a bronchodilator challenge test and were invited (if eligible) to undergo a methacholine challenge test on a second occasion. Atopy was assessed by SPT to common allergens ${ }^{(27)}$.

\section{Dietary exposure assessment: flavonoid intake estimates}

All exposure measurements were assessed following standard procedures that included previously validated questionnaires. Information on dietary intake was collected using the Italian version of the validated European Prospective Investigation into Cancer and Nutrition (EPIC) FFQ, which was based on Italian dietary habits and developed in the frame of an international survey ${ }^{(28)}$. The NAF (Nutritional Analysis of Food Frequency Questionnaires, National Cancer Institute, Milan, Italy) software $^{(29)}$ was used to compute the daily intakes of food items, energy, macro- and micronutrients. Nutrient data for specific foods were obtained from the food composition database for epidemiological studies in Italy ${ }^{(30)}$. Information on flavonoid intake was derived from the foods contained in the FFQ (mostly plant-derived). Estimates for intakes of total flavonoids and seven major subclasses (flavanones, anthocyanins, flavan-3-ols, flavonols, flavones, polymers and proanthocyanidins), expressed as aglycones (mg/d), were derived from sixtyfive foods (see online supplementary material, Supplemental Table S1) using the US Department of Agriculture's updated and expanded flavonoid content of foods and proanthocyanidin databases ${ }^{(31,32)}$.

Overall, out of the 2749 individuals participating in the clinical stage of the survey, 1182 (43\%) filled in the FFQ. Forty-three individuals with incomplete FFQ (less than $80 \%$ of the 434 questions and nested questions of the FFQ filled in) were excluded from the analyses. We estimated BMR using sex-specific equations for adults $(\leq 60 \text { years old })^{(33)}$ and the elderly $(>60 \text { years old })^{(34)}$. Twenty-four individuals were excluded as BMR could not be computed due to missing data. Individuals were also excluded if they had extreme values of total energy intake (EI), which might suggest an unrealistic response: we excluded those with a ratio of EI to expected BMR below the 0.5 th sample centile or above the 99.5th sample centile. Eight individuals were excluded according to the cut-off points on the top (four persons) and bottom (four persons) 0.5 th percentile of the distribution of EI: BMR. Ten individuals (five women and five men) with extremely low EI levels ( $<2510 \mathrm{~kJ}$ ( $<600 \mathrm{kcal})$ for women and $3347 \mathrm{~kJ}(<800 \mathrm{kcal})$ for men) were excluded from the analyses ${ }^{(35)}$ (Fig. 1). 


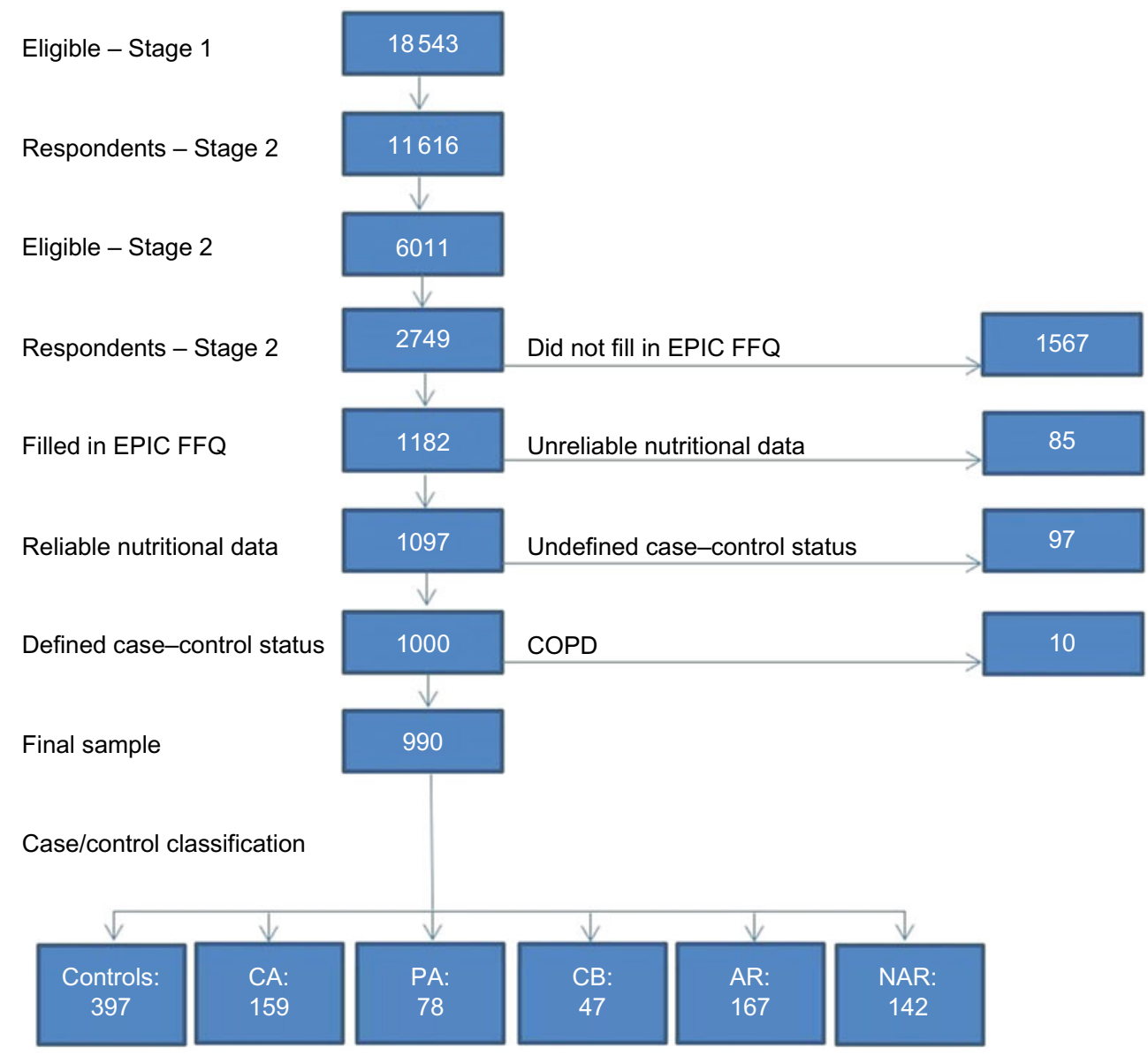

Fig. 1 (colour online) Flowchart of participant selection (EPIC, European Prospective Investigation into Cancer and Nutrition; COPD, chronic obstructive pulmonary disease; $\mathrm{CA}$, current asthma; PA, past asthma; $\mathrm{CB}$, chronic bronchitis; AR, allergic rhinitis; NAR, non-allergic rhinitis)

\section{Identification of cases and controls in clinics}

The sample for the current analysis included 1097 individuals (Fig. 1) with information on the clinical visit and on food and nutrient intakes, who were hierarchically classified as follows.

1. One hundred and fifty-nine cases of current asthma (CA):

a. he/she reported a history of asthma AND asthma-like symptoms/medicines in the last 12 months;

b. he/she reported a history of asthma OR asthmalike symptoms/medicines in the last 12 months plus one of the following conditions: (i) he/she had a positive methacholine challenge test with a provocative dose of methacholine causing a $20 \%$ drop in $\mathrm{FEV}_{1}\left(\mathrm{PD}_{20}\right)$ of $<1 \mathrm{mg}$; (ii) he/she had pre-bronchodilator $\mathrm{FEV}_{1} / \mathrm{FEC}<70 \%$ or $<\operatorname{LLN}^{(25)}$ with a positive reversibility test (i.e. $\mathrm{FEV}_{1}>12 \%$ and $>200 \mathrm{ml}$ after the administration of $400 \mu \mathrm{g}$ salbutamol); (iii) he/she had prebronchodilator $\mathrm{FEV}_{1} / \mathrm{FEC}<70 \%$ or $<\mathrm{LLN}$ with a post-bronchodilator $\mathrm{FEV}_{1} / \mathrm{FVC}>\mathrm{LLN}$ and
$>70 \%$ and a post-bronchodilator $\mathrm{FEV}_{1}>80 \%$ predicted $^{(25)}$.

2. Seventy-eight cases of past asthma (PA): he/she reported a history of asthma but did not fulfil the criteria for CA.

3. Ten cases of COPD: post-bronchodilator $\mathrm{FEV}_{1} /$ FEC $<70 \%$ or $<$ LLN without asthma.

4. Forty-seven cases of CB: he/she was not a COPD or asthma case and he/she reported chronic cough or phlegm (>3 months/year for at least 2 years).

5. One hundred and sixty-seven cases of allergic rhinitis (AR) and 125 cases of non-allergic rhinitis (NAR): he/she had nasal allergies or nasal problems in the presence of animal(s), pollens and/or dust, plus a negative SPT (NAR) or a positive SPT to at least one allergen (AR).

6. Three hundred and ninety-seven controls: individuals without any nasal/respiratory symptoms/conditions reported in the clinical questionnaire neither in the clinic nor in the screening questionnaire, who were not cases and had both (i) pre-bronchodilator $\mathrm{FEV}_{1} / \mathrm{FVC}>\mathrm{LLN}$ and $>70 \%$; and (ii) $\mathrm{FEV}_{1}>70 \%$ predicted. 
Ninety-seven individuals were unclassified due to missing data.

Individuals with COPD and unclassified individuals were excluded from the present analyses, therefore the final sample included 990 participants. Due to the hierarchical classification, cases of CA and PA could also present $\mathrm{COPD} / \mathrm{CB} / \mathrm{AR} / \mathrm{NAR}$; cases of $\mathrm{CB}$ could present AR/NAR.

\section{Statistical analyses}

Participant characteristics were summarized as percentages, or as medians and interquartile ranges (IQR), or means and standard deviations; flavonoid and food intakes were summarized as medians and IQR. The $\chi^{2}$ test, Kruskal-Wallis test and Student's $t$ test were used to test differences $(\alpha=0.05)$, where appropriate. The main exposures of interest (total flavonoids and each subclass) were considered as continuous variables and analysed for a variation of one standard deviation. Exposures were also categorized into quartiles based on the distribution of the exposure in controls. Quartiles allow the comparison of extreme groups, such as those with highest and lowest intakes of nutrients or foods, and are less sensitive to the effects of outliers than continuous variables. On the other hand, the estimates of measures of disease risk related to dietary exposures expressed as continuous variables make easier the comparison of evidence obtained in different studies.

To analyse the associations between each flavonoid class and case-control status, several multinomial logistic regression models were fitted to the data, using a six-level variable (CA, PA, CB, AR, NAR, control) as outcome. Multivariable associations of exposures with case-control status were expressed by relative risk ratios (RRR; using control as the reference category) and their $95 \%$ confidence intervals. Analyses were adjusted for study sample/cohort (ISAYA, ECRHS-Italy, new random sample), centre (Verona, Pavia, Torino and Sassari), gender, age, BMI, education (low $=$ completed before the age of 16 years; high $=$ completed after the age of 16 years) as a proxy of socio-economic status, smoking habit (never smoker; past smoker, i.e. not smoking in the last month; current smoker), alcohol intake $(\mathrm{g} / \mathrm{d})$, total energy intake ( $\mathrm{kcal} / \mathrm{d})$, vitamin $\mathrm{C}$ intake $(\mathrm{mg} / \mathrm{d})$ and total fruit intake $(\mathrm{g} / \mathrm{d})$. The analyses were performed using the statistical software package Stata version 14.2.

\section{Results}

Among the groups of cases and controls, we found no differences in terms of age (overall mean: $50 \cdot 7$ (SD 12.3) years), gender (overall proportion of males: $48.79 \%$ ), BMI (overall median: $24 \cdot 7$ (IQR $22 \cdot 3-27 \cdot 7$ ) kg/m²), physical activity and educational level (Table 1 ).

Comparing the characteristics of the individuals who fulfilled the EPIC FFQ ( $n$ 1182) and those who did not ( $n 1567)$, we found that mean age was significantly higher in the groups of controls, CA and AR among individuals who fulfilled the questionnaire (51.0 (SD 12.0),

Table 1 General characteristics of the participants: adults from the GEIRD (Genes Environment Interaction in Respiratory Diseases) population-based multi-case-control study in Pavia, Torino, Sassari and Verona, Italy, 2007-2010

\begin{tabular}{|c|c|c|c|c|c|c|c|}
\hline & Controls $(n 397)$ & $\mathrm{CA}(n 159)$ & $\mathrm{PA}(n 78)$ & $\mathrm{CB}(n 47)$ & $\mathrm{AR}(n 167)$ & NAR $(n 142)$ & $P$ value \\
\hline Age at the clinical visit (years) & & & & & & & 0.726 \\
\hline Mean & 51.9 & 50.5 & $45 \cdot 2$ & $49 \cdot 1$ & $49 \cdot 7$ & $52 \cdot 3$ & \\
\hline SD & $12 \cdot 0$ & $12 \cdot 6$ & 11.3 & $13 \cdot 7$ & $12 \cdot 5$ & $12 \cdot 0$ & \\
\hline Gender (\% male) & $48 \cdot 36$ & $49 \cdot 69$ & 44.87 & $55 \cdot 32$ & $52 \cdot 69$ & 44.37 & 0.625 \\
\hline Smoking habits (\%) & & & & & & & 0.013 \\
\hline Non-smoker & 53.79 & $50 \cdot 31$ & $57 \cdot 14$ & 44.68 & $57 \cdot 49$ & 43.66 & \\
\hline Ex-smoker & 32.58 & $27 \cdot 67$ & $27 \cdot 27$ & 21.28 & $26 \cdot 35$ & 34.51 & \\
\hline Current smoker & $13 \cdot 64$ & $22 \cdot 01$ & $15 \cdot 58$ & 34.04 & $16 \cdot 17$ & 21.83 & \\
\hline Drinking habits (\%) & & & & & & & 0.018 \\
\hline Current drinker & $35 \cdot 10$ & $47 \cdot 17$ & $37 \cdot 18$ & 57.45 & $40 \cdot 72$ & $41 \cdot 13$ & \\
\hline Abstainer & 64.03 & $52 \cdot 2$ & $62 \cdot 82$ & 41.30 & $59 \cdot 51$ & 56.74 & \\
\hline Ex-drinker & 1.53 & 0.63 & 0.00 & $2 \cdot 17$ & $1 \cdot 23$ & $2 \cdot 13$ & \\
\hline Total alcohol (\%) & & & & & & & 0.023 \\
\hline$<5 \mathrm{~g} / \mathrm{d}$ & 6.63 & 14.47 & $10 \cdot 26$ & $10 \cdot 87$ & 5.52 & $13 \cdot 48$ & \\
\hline $5-<15 \mathrm{~g} / \mathrm{d}$ & $17 \cdot 60$ & $16 \cdot 98$ & 17.95 & $19 \cdot 57$ & $15 \cdot 95$ & 13.48 & \\
\hline $15-<30 \mathrm{~g} / \mathrm{d}$ & $6 \cdot 12$ & $10 \cdot 06$ & 6.41 & 13.04 & 13.50 & $10 \cdot 64$ & \\
\hline $30-120 \mathrm{~g} / \mathrm{d}$ & 4.08 & $5 \cdot 66$ & 2.56 & 13.04 & 4.29 & 3.55 & \\
\hline BMl $\left(\mathrm{kg} / \mathrm{m}^{2}\right)$ & & & & & & & 0.692 \\
\hline Median & $25 \cdot 0$ & 24.8 & 23.9 & 25.5 & 24.3 & $24 \cdot 6$ & \\
\hline IQR & $22 \cdot 4-27 \cdot 7$ & $22 \cdot 0-27 \cdot 6$ & $21 \cdot 9-27 \cdot 0$ & $22 \cdot 1-28 \cdot 6$ & $22 \cdot 6-27 \cdot 2$ & $22 \cdot 2-28 \cdot 0$ & \\
\hline Physical activity (\%) & & & & & & & 0.35 \\
\hline Heavy & $5 \cdot 79$ & 4.40 & 6.41 & $10 \cdot 64$ & 8.98 & 6.34 & \\
\hline Moderate & $36 \cdot 27$ & $35 \cdot 22$ & 32.05 & 27.66 & $41 \cdot 32$ & 42.25 & \\
\hline Light & 57.93 & $60 \cdot 38$ & 61.54 & $61 \cdot 70$ & $49 \cdot 70$ & 51.41 & \\
\hline Education level (\% high) & 75.95 & 75.95 & 87.18 & $70 \cdot 21$ & 78.44 & 68.79 & 0.056 \\
\hline
\end{tabular}

$\mathrm{CA}$, current asthma; PA, past asthma; $\mathrm{CB}$, chronic bronchitis; $\mathrm{AR}$, allergic rhinitis; NAR, non-allergic rhinitis; IQR, interquartile range. 
50.5 (SD 12.6) and 49.7 (SD 12.5) years, respectively) compared with the individuals who did not ( 49.7 (SD 12.9), 45.2 (SD 11.8) and 46.9(SD 12.7) years, respectively; see online supplementary material, Supplemental Table S2).

Among participants included in the analysis, we found that smoking habits, drinking habits and alcohol intake varied significantly across the groups $(P=0.013,0.018$ and 0.023 , respectively), with the highest proportion of drinkers and current smokers in the group affected by $\mathrm{CB}$ ( 57.45 and $34.04 \%$, respectively). There were no statistically significant differences in the intakes of total or subclasses of flavonoids across the case groups (overall median total flavonoids intake: $382 \cdot 1$ (IQR 248.8-529.8) $\mathrm{mg}$ ) and in the intakes of foods rich in flavonoids (Table 2). Overall median fruit and vegetable intakes were 289.1 (IQR 191.9$425.5) \mathrm{g} / \mathrm{d}$ and 130.2 (IQR 86.7-194.5) g/d, respectively. There were no statistically significant differences in the intakes of total energy intake and vitamin $\mathrm{C}$ across the groups (overall median energy intake: 7988.5 (IQR 6299.0$10037.0) \mathrm{kJ} / \mathrm{d}$ (1909.3 (IQR 1505.5-2398.9) kcal/d); overall median vitamin C intake: $117 \cdot 6$ (IQR 82.6-161.9) mg/d).

In the unadjusted continuous regression analyses, there were no significant associations between any of the flavonoid subclasses and the outcomes considered (Table 3). After adjustment, we found that an increase of $1 \mathrm{sD}$ in intake of flavanones, equivalent to $26 \cdot 1 \mathrm{mg} / \mathrm{d}$, was associated with a reduced risk of NAR $(R R R=0.68$, $95 \%$ CI 0.47, 0.97). Similarly, adjusted analyses exploring the exposures per quartile showed that those in the highest $v$. lowest quartile of flavanone intake had a reduced risk of NAR (RRR $=0.24,95 \%$ CI $0.10,0.59$ ). We found no consistent evidence of an association between a high intake of other subclasses of flavonoids and the risk of any of the other outcomes.

\section{Discussion}

In this multi-case-control study of Italian adults from the general population, we found that having a higher intake of flavanones was associated with a reduced risk of NAR. The association was statistically significant when the groups were examined as the highest $v$. lowest quartile of intake and when the intake was analysed as a continuous exposure.

Flavonoids have been described to have anti-inflammatory and antioxidant properties ${ }^{(7-13)}$. Airway inflammation, which is exacerbated by oxidative stress ${ }^{(14)}$, is known to be related to the pathogenesis and worsening of pulmonary diseases ${ }^{(2,36)}$. In our study, we considered asthma, $\mathrm{CB}$ and rhinitis, diseases in which airway inflammation plays a key role ${ }^{(37)}$. Depending on the severity of asthma, inflammation can affect the large and small airways ${ }^{(2)}$. Similarly, in $\mathrm{CB}$, inflammation affects the lumen and the wall of the airways ${ }^{(38)}$. Experimental studies show that flavonoids can counteract the oxidative stress and inflammation caused by environmental insult to the airways. Quercetin, one of the most investigated flavonoids, has been shown to reduce superoxides and nitric oxide radicals, which are mediators of inflammation ${ }^{(39,40)}$. Flavonoids can inhibit the metabolism of arachidonic acid, which is involved in the production of reactive oxygen species $^{(10,41)}$. Moreover, they seem to reduce the adhesion of inflammatory cells ${ }^{(14)}$.

In spite of the large body of experimental evidence supporting an association of flavonoid intake with respiratory diseases, epidemiological studies are still scant and have reported mixed results, which might partly be explained by the different types of flavonoids studied ${ }^{(42)}$. Several population-based studies have suggested that higher intakes of foods rich in flavonoids (mainly fruits, vegetables, wine and tea) were associated with a lower risk of asthma ${ }^{(1,43)}$, although this association has not been confirmed in other studies ${ }^{(44)}$. The few population-based studies that have examined the association of flavonoid intake and airways disease are limited and the evidence is inconclusive. Tabak et al. reported that a higher intake of catechins was associated with a lower risk of COPD and asthma in a population of Dutch adults ${ }^{(45)}$. Garcia et al. found no evidence of an association of three subclasses of flavonoids with asthma or $\mathrm{CB}$ in a populationbased case-control study in London ${ }^{(20)}$. Moreover, a recent clinical trial on both adults and children with poor asthma control revealed no association between the supplementary use of soya isoflavone and lung function ${ }^{(46)}$.

The recent hypothesis that microbiota might play a role to protect against inflammation-mediated airways diseases was investigated in a small sample of twenty-three allergic individuals ${ }^{(47)}$. The study showed that a higher intake of a diet rich in phenolic compounds was associated with a more stable gut microbiota, which might contribute to the management of allergic conditions through a reduced inflammation. A recent cohort study reported that a higher intake of soya genistein was associated with improved lung function and asthma control in individuals with stable asthma ${ }^{(48)}$. Evidence from human trials is also limited. A recent randomized controlled trial found no evidence that supplementation with soya genistein had any effect on outcomes of asthma or lung function in adults with unstable asthma ${ }^{(46)}$, while in an intervention in forty-two asthmatic adults, a passion fruit puree extract rich in bioflavonoids reduced the severity of asthma symptoms ${ }^{(49)}$.

In our study, we found limited evidence to suggest that flavonoids are associated with airways disease. The individuals in our population-based study had stable asthma, CB or AR. It might be possible that the beneficial effect of flavonoids occurs in cases of greater chronic airway inflammation, which is usually reduced in stable patients. We found a statistically significant negative association of flavanones with non-atopic rhinitis. The association with atopic rhinitis was also negative in both approaches used, but not statistically significant. Atopy in 
Table 2 Distribution of the dietary flavonoid, food and nutrient intakes studied, according to case or control status, among adults from the GEIRD (Genes Environment Interaction in Respiratory Diseases) population-based multi-case-control study in Pavia, Torino, Sassari and Verona, Italy, 2007-2010

\begin{tabular}{|c|c|c|c|c|c|c|c|c|c|c|c|c|c|}
\hline & \multicolumn{2}{|c|}{ Controls (n 397) } & \multicolumn{2}{|c|}{ CA $(n 159)$} & \multicolumn{2}{|c|}{$\mathrm{PA}(n 78)$} & \multicolumn{2}{|r|}{$\mathrm{CB}(n 47)$} & \multicolumn{2}{|c|}{ AR $(n 167)$} & \multicolumn{2}{|c|}{ NAR $(n 142)$} & \multirow{2}{*}{$\begin{array}{c}P \\
\text { value }\end{array}$} \\
\hline & Median & IQR & Median & IQR & Median & IQR & Median & IQR & Median & IQR & Median & IQR & \\
\hline \multicolumn{14}{|l|}{ Flavonoids (mg/d) } \\
\hline Total flavonoids & 381.9 & $255 \cdot 1-526 \cdot 5$ & $388 \cdot 3$ & $258 \cdot 4-554.9$ & 380.9 & $212 \cdot 1-517 \cdot 5$ & 374.5 & $198 \cdot 5-515 \cdot 1$ & 365.6 & $238 \cdot 2-545 \cdot 5$ & $394 \cdot 2$ & $277 \cdot 4-518 \cdot 4$ & 0.98 \\
\hline Flavanones & $27 \cdot 3$ & $14 \cdot 0-45 \cdot 8$ & $27 \cdot 1$ & $12 \cdot 8-43 \cdot 3$ & $28 \cdot 1$ & $11 \cdot 1-36.5$ & $23 \cdot 2$ & $12 \cdot 3-38 \cdot 7$ & $28 \cdot 0$ & $18 \cdot 3-40 \cdot 3$ & $26 \cdot 7$ & $13 \cdot 4-38.5$ & 0.75 \\
\hline Anthocyanins & $17 \cdot 3$ & $10 \cdot 0-28 \cdot 4$ & $15 \cdot 7$ & $8 \cdot 8-27 \cdot 7$ & $16 \cdot 6$ & $10 \cdot 7-24 \cdot 8$ & $15 \cdot 4$ & $6 \cdot 2-25 \cdot 4$ & $15 \cdot 9$ & $10 \cdot 3-25 \cdot 7$ & $17 \cdot 8$ & $9 \cdot 3-28 \cdot 0$ & 0.92 \\
\hline Flavan-3-ols & $45 \cdot 5$ & $26 \cdot 7-71.9$ & $46 \cdot 0$ & $27 \cdot 7-75 \cdot 2$ & $48 \cdot 2$ & $26 \cdot 7-72 \cdot 3$ & $42 \cdot 9$ & $28 \cdot 2-85 \cdot 8$ & $46 \cdot 6$ & $25 \cdot 4-73 \cdot 4$ & $47 \cdot 7$ & $29 \cdot 2-80 \cdot 1$ & 0.93 \\
\hline Flavonols & $15 \cdot 9$ & $10 \cdot 8-21 \cdot 7$ & $15 \cdot 1$ & $10 \cdot 4-20 \cdot 0$ & $15 \cdot 1$ & $10 \cdot 6-21 \cdot 7$ & $17 \cdot 0$ & $10 \cdot 8-23 \cdot 8$ & $15 \cdot 2$ & $9 \cdot 6-21 \cdot 7$ & $15 \cdot 8$ & $10 \cdot 2-20 \cdot 7$ & 0.86 \\
\hline Flavones & 1.9 & $1 \cdot 1-2 \cdot 9$ & $2 \cdot 0$ & $1 \cdot 2-3 \cdot 2$ & 1.9 & $1 \cdot 3-2 \cdot 8$ & 1.9 & $1 \cdot 2-2 \cdot 7$ & 1.9 & $1 \cdot 0-2 \cdot 8$ & 1.9 & $1 \cdot 0-3 \cdot 0$ & 0.94 \\
\hline Polymers & 269.4 & $168 \cdot 6-370 \cdot 6$ & $261 \cdot 3$ & $168 \cdot 6-403 \cdot 2$ & $267 \cdot 7$ & $138 \cdot 3-380 \cdot 5$ & 257.7 & $146 \cdot 1-350 \cdot 9$ & $247 \cdot 7$ & $157 \cdot 3-377 \cdot 4$ & 254.6 & $174 \cdot 7-370 \cdot 0$ & 0.98 \\
\hline Proanthocyanidins & 293.0 & $188 \cdot 6-417 \cdot 2$ & $295 \cdot 3$ & $188 \cdot 2-461 \cdot 4$ & 293.3 & $154 \cdot 2-420 \cdot 0$ & $292 \cdot 0$ & $163 \cdot 0-405 \cdot 5$ & $279 \cdot 3$ & $178 \cdot 0-432 \cdot 5$ & $289 \cdot 0$ & $197 \cdot 3-422 \cdot 1$ & 0.98 \\
\hline \multicolumn{14}{|l|}{ Foods $(g / d)$} \\
\hline Fruits & $302 \cdot 6$ & $203 \cdot 0-433 \cdot 0$ & 288.4 & $193 \cdot 3-424 \cdot 1$ & 275.35 & $168 \cdot 8-425 \cdot 7$ & 211.4 & $142 \cdot 6-398 \cdot 6$ & $290 \cdot 2$ & $200 \cdot 1-401 \cdot 6$ & $280 \cdot 75$ & $188 \cdot 6-429 \cdot 0$ & 0.22 \\
\hline Vegetables & 129.0 & $79 \cdot 8-195 \cdot 1$ & $118 \cdot 6$ & $81 \cdot 4-190 \cdot 9$ & 150.95 & $105 \cdot 2-232 \cdot 0$ & $152 \cdot 1$ & $101 \cdot 1-196 \cdot 3$ & $128 \cdot 7$ & $89 \cdot 4-182 \cdot 5$ & 131.05 & $91 \cdot 1-195 \cdot 2$ & 0.18 \\
\hline Chocolate & $2 \cdot 7$ & $0.0-8.6$ & 2.9 & $0.7-12 \cdot 8$ & 2.9 & $0.7-11.4$ & 2.9 & $1 \cdot 3-10 \cdot 3$ & $3 \cdot 7$ & $0.7-8.6$ & 3.7 & $0.7-11.4$ & 0.12 \\
\hline Red wine & 4.2 & $0.0-62.5$ & 13.9 & $0 \cdot 0-107 \cdot 1$ & $8 \cdot 1$ & $0.0-62.5$ & $4 \cdot 2$ & $0.0-79.4$ & 8.3 & $0.0-63.5$ & 1.9 & $0.0-59.5$ & 0.47 \\
\hline White wine & 1.4 & $0 \cdot 0-26 \cdot 8$ & $2 \cdot 1$ & $0.0-41.7$ & 3.5 & $0 \cdot 0-35 \cdot 7$ & 0.5 & $0 \cdot 0-26 \cdot 8$ & 1.0 & $0 \cdot 0-26 \cdot 8$ & 1.0 & $0 \cdot 0-26 \cdot 8$ & 0.74 \\
\hline Tea & $10 \cdot 0$ & $0.0-85 \cdot 7$ & $5 \cdot 0$ & $0.0-64.3$ & $10 \cdot 0$ & $0.0-64 \cdot 3$ & $15 \cdot 0$ & $0 \cdot 0-150$ & $15 \cdot 0$ & $0.0-85 \cdot 7$ & $10 \cdot 0$ & $0 \cdot 0-150$ & 0.52 \\
\hline \multicolumn{14}{|l|}{ Nutrients } \\
\hline Vitamin C (mg/d) & $116 \cdot 3$ & $83 \cdot 4-162 \cdot 8$ & $116 \cdot 9$ & $84 \cdot 0-156 \cdot 4$ & $129 \cdot 3$ & $79 \cdot 8-167 \cdot 8$ & $105 \cdot 3$ & $71.5-151.7$ & $119 \cdot 4$ & $84 \cdot 6-164 \cdot 4$ & $118 \cdot 9$ & $80 \cdot 9-165 \cdot 4$ & 0.84 \\
\hline $\begin{array}{l}\text { Total energy intake } \\
(\mathrm{kJ} / \mathrm{d})\end{array}$ & $7849 \cdot 6$ & $6123 \cdot 7-9989 \cdot 3$ & $7666 \cdot 8$ & $6353 \cdot 4-9288 \cdot 9$ & $8986 \cdot 4$ & $6875 \cdot 1-10732 \cdot 8$ & $8892 \cdot 3$ & $6377 \cdot 3-11621 \cdot 1$ & $8217 \cdot 4$ & $6602 \cdot 4-9699 \cdot 3$ & $7728 \cdot 3$ & $6278 \cdot 9-10132 \cdot 8$ & $0 \cdot 13$ \\
\hline $\begin{array}{l}\text { Total energy } \\
\text { intake }(\mathrm{kcal} / \mathrm{d})\end{array}$ & $1876 \cdot 1$ & $1463 \cdot 6-2387 \cdot 5$ & $1832 \cdot 4$ & $1518 \cdot 5-2220 \cdot 1$ & $2147 \cdot 8$ & $1643 \cdot 2-2565 \cdot 2$ & $2125 \cdot 3$ & $1524 \cdot 2-2777 \cdot 5$ & $1964 \cdot 0$ & $1578 \cdot 0-2318 \cdot 2$ & $1847 \cdot 1$ & $1500 \cdot 7-2421 \cdot 8$ & 0.13 \\
\hline
\end{tabular}

CA, current asthma; PA, past asthma; $\mathrm{CB}$, chronic bronchitis; AR, allergic rhinitis; NAR, non-allergic rhinitis; IQR, interquartile range. 
Table 3 Unadjusted and adjusted* relative risk ratios (RRR) and $95 \%$ confidence intervals of being a respiratory disease case rather than a control ( $n 397)$, according to the intake of flavonoidst, among adults from the GEIRD (Genes Environment Interaction in Respiratory Diseases) population-based multi-case-control study in Pavia, Torino, Sassari and Verona, Italy, 2007-2010

\begin{tabular}{|c|c|c|c|c|c|c|c|c|c|c|}
\hline \multirow{2}{*}{$\begin{array}{l}\text { Flavonoid intake } \\
\text { (per mg/d increase of } 1 \mathrm{SD} \text { ) }\end{array}$} & \multicolumn{2}{|c|}{ CA $(n 159)$} & \multicolumn{2}{|c|}{$\mathrm{PA}(n 78)$} & \multicolumn{2}{|c|}{$\mathrm{CB}(n 47)$} & \multicolumn{2}{|c|}{$\mathrm{AR}(n 167)$} & \multicolumn{2}{|c|}{ NAR $(n 142)$} \\
\hline & RRR & $95 \% \mathrm{Cl}$ & RRR & $95 \% \mathrm{Cl}$ & RRR & $95 \% \mathrm{Cl}$ & RRR & $95 \% \mathrm{Cl}$ & RRR & $95 \% \mathrm{Cl}$ \\
\hline Total flavonoids (unadjusted) & 0.98 & $0.81,1.18$ & 0.94 & $0.73,1.21$ & 0.94 & $0.69,1.28$ & 0.93 & $0.77,1.12$ & 0.99 & $0.82,1.20$ \\
\hline Total flavonoids (adjusted & 1.05 & $0.80,1.37$ & 0.92 & $0.65,1.30$ & $1 \cdot 12$ & $0.72,1.73$ & 0.94 & $0.72,1.22$ & 1.02 & $0.77,1.34$ \\
\hline Flavanones (unadjusted) & 1.01 & $0.85,1.20$ & 0.80 & $0.60,1.07$ & 0.81 & $0.57,1.16$ & 0.98 & $0.82,1.17$ & 0.86 & $0.69,1.06$ \\
\hline Flavanones (adjusted) & 1.09 & $0.81,1.45$ & & $0.42,1.08$ & & & 0.88 & & 0.68 & $0.47,0$ \\
\hline hocyanins (unadjusted) & & & & $0.73,1.19$ & & & & & & \\
\hline & .83 & $0.62,1 \cdot 11$ & $1 \cdot 14$ & $0.76,1.71$ & 0.97 & & 0.93 & $0.70,1.25$ & 0.98 & $0.71,1$ \\
\hline Flavan-3-ols (unadjusted) & 0.98 & $0.81,1.19$ & 0.98 & $0 \cdot 76,1.27$ & 1.05 & $0.78,1.41$ & 0.93 & $0.76,1.13$ & 1.04 & $0.86,1.26$ \\
\hline Flavan-3-ols (adjusted) & 0.98 & $0.79,1.22$ & 0.89 & $0.66,1.20$ & 1.08 & $0.76,1.54$ & 0.92 & $0.74,1.15$ & 1.06 & $0.86,1.32$ \\
\hline Flavonols (unadjusted) & 0.88 & $0.72,1.07$ & 0.93 & $0.72,1.20$ & 1.20 & $0.92,1.56$ & 0.93 & $0.77,1.12$ & 0.97 & $0.80,1.18$ \\
\hline Flavonols (adjusted) & 0.81 & $0.63,1.06$ & 0.98 & $0.71,1.36$ & 1.37 & $0.97,1.94$ & 0.88 & $0.69,1$ & 0.94 & $0.73,1.21$ \\
\hline Flavones (unadjusted) & 1.04 & $0.87,1.24$ & 0.94 & $0.73,1.21$ & $1 \cdot 14$ & & 0.94 & $8,1 \cdot 13$ & 0.96 & $9,1 \cdot 16$ \\
\hline djusted) & 0.93 & $0.71,1.22$ & 1.03 & $0.71,1.51$ & 1.00 & $0.69,1.47$ & 0.81 & $0.62,1.07$ & 0.95 & $0.71,1.27$ \\
\hline Polymers (unadjusted) & 0.98 & $0.82,1.18$ & 0.96 & $0.75,1.23$ & 0.93 & $0.67,1.27$ & 0.93 & $0.77,1.12$ & 1.01 & $0.83,1.22$ \\
\hline Polymers (adjusted) & 1.08 & $0.84,1.39$ & 0.97 & $0.70,1.33$ & 1.09 & $0.72,1.66$ & 0.98 & $0.76,1.26$ & 1.03 & $0.80,1.34$ \\
\hline Proanthocyanidins (unadjusted) & 1.02 & $0.85,1.22$ & 0.96 & $0.75,1.24$ & 0.95 & $0.69,1.30$ & 0.95 & $0.79,1.15$ & 1.01 & $0.83,1.22$ \\
\hline Proanthocyanidins (adjusted) & $1 \cdot 11$ & $0.88,1.41$ & 0.95 & $0.69,1.29$ & 1.05 & $0.70,1.58$ & 1.00 & $0.78,1.26$ & 1.03 & $0.81,1.32$ \\
\hline
\end{tabular}

$\mathrm{CA}$, current asthma; PA, past asthma; $\mathrm{CB}$, chronic bronchitis; AR, allergic rhinitis; NAR, non-allergic rhinitis.

${ }^{\star}$ The estimates were adjusted for age, gender, centre, study cohort, BMI, smoking habits, alcohol intake, educational level, total fruit intake, vitamin $\mathrm{C}$ intake and total energy intake.

†Significant results are shown in bold.

those affected by rhinitis is defined on the basis of an SPT, which measures the systemic presence of serum allergenspecific IgE in allergic individuals. However, it has also been found in individuals affected by non-atopic rhinitis that allergen-specific IgE can be found locally in the nasal mucosa, which is not detectable through an $\mathrm{SPT}^{(50)}$. Flavonoids are thought to inhibit the formation of $\operatorname{IgE}^{(9,18)}$ and this might explain the positive effect found on individuals with non-atopic rhinitis in the present study.

Our study did not confirm an association of any of the flavonoid subclasses studied with $\mathrm{CB}$, which is in line with the results reported in an earlier case-control study in the general population ${ }^{(20)}$. Anthocyanin intake was associated with a reduced risk of $\mathrm{CB}$, but this did not reach statistical significance. Although inflammation is a central feature in $\mathrm{CB}$, it might be possible that avoidance of environmental pollutants and related environmental insult might be the best effective way to reduce the risk of this disease ${ }^{(38)}$.

Some observational studies have analysed the association between flavonoids and atopic rhinitis. The extract of French maritime bark, which is rich in flavonoids, appeared to reduce eye and nasal symptoms, but the results were limited by the small sample of participants ${ }^{(51)}$. In another clinical trial, a preventive effect of enzymatically modified isoquercitrin was found on ocular symptoms, but not on nasal symptoms ${ }^{(52)}$.

Our study has several strengths. We considered several chronic respiratory diseases, giving a wide view of the possible role of flavonoids in different pulmonary health conditions. Case and control status was assessed in a two-stage process; first by a screening questionnaire on symptoms and use of medicines, then through a clinical visit $^{(21)}$. The EPIC FFQ was validated through comparison with multiple interviews and the analysis of nitrogen in urine samples ${ }^{(28)}$. We analysed the associations between flavonoid intakes and chronic respiratory diseases considering seven subclasses of flavonoids, computed using data from the US Department of Agriculture database, which provides updated information of flavonoid contents of foods.

We acknowledge some limitations to the study. Having five case groups and only one control group might have reduced the power to detect statistically significant differences between the participants. Moreover, we defined the potential confounders a priori based on pre-existing knowledge on their relationship with flavonoids and with the outcomes evaluated; however, residual confounding may still exist. The Italian version of the EPIC FFQ provides an extensive list of foods with high content of flavonoids, which allowed us to derive estimates for all major subclasses. However, the earlier validation study of the Italian version of the EPIC FFQ showed modest levels of agreement in the intakes of macronutrients and some foods, and has not been validated specifically for flavonoid intake ${ }^{(28)}$. Finally, we used data from a single FFQ and assumed that adults maintained relatively stable dietary habits to investigate disease risk $^{(53)}$.

Overall, the results of the present population-based, multi-case-control study suggest that intake of flavanones is negatively associated with the risk of having NAR. No associations were found between other flavonoids and the considered outcomes. 


\section{Acknowledgements}

Acknowledgements: The authors are indebted to all the individuals of the GEIRD study for their participation. Financial support: The GEIRD project was funded by the Cariverona Foundation; the Italian Ministry of Health; Chiesi Farmaceutici; and the Italian Medicines Agency (AIFA). The funders had no role in the design; in the collection, analysis and interpretation of the data; in the writing of the manuscript; and in the decision to submit the manuscript for publication. Conflict of interest: The authors declare no conflict of interest. Authorship: V.G.-L., M.E.Z. and L.C. conceived and designed the study. L.C., M.E.Z., R.B., I.C., P.P. and M.F. contributed to the data collection. V.M. performed the statistical analysis. L.C., M.E.Z. and V.M. drafted the manuscript. L.C., M.E.Z., V.G.-L., A.G., V.M., P.P. and M.F. contributed to the interpretation of data, revised the paper critically for important intellectual content and approved the version to be published. Ethics of buman subject participation: This study was conducted according to the guidelines laid down in the Declaration of Helsinki and all procedures involving human subjects were approved by the ethics committee of Azienda Ospedaliera of Verona, as coordinating centre. Written informed consent was obtained from all subjects.

\section{Supplementary material}

To view supplementary material for this article, please visit https://doi.org/10.1017/S1368980019003562

\section{References}

1. Hosseini B, Berthon BS, Wark P et al. (2017) Effects of fruit and vegetable consumption on risk of asthma, wheezing and immune responses: a systematic review and meta-analysis. Nutrients 9, 341 .

2. MacNee W (2001) Oxidative stress and lung inflammation in airways disease. Eur J Pharmacol 429, 195-207.

3. Garcia-Larsen V, Del Giacco SR, Moreira A et al. (2016) Asthma and dietary intake: an overview of systematic reviews. Allergy 71, 433-442.

4. Seyedrezazadeh E, Moghaddam MP, Ansarin K et al. (2014) Fruit and vegetable intake and risk of wheezing and asthma: a systematic review and meta-analysis. Nutr Rev 72, 411-428.

5. Butland BK, Strachan DP \& Anderson HR (1999) Fresh fruit intake and asthma symptoms in young British adults: confounding or effect modification by smoking? Eur Respir $J \mathbf{1 3}, 744-750$.

6. Uddenfeldt M, Janson C, Lampa E et al. (2010) High BMI is related to higher incidence of asthma, while a fish and fruit diet is related to a lower - results from a long-term followup study of three age groups in Sweden. Respir Med 104, 972-980.

7. Ferk F, Misik M, Nersesyan A et al. (2016) Impact of xanthohumol (a prenylated flavonoid from hops) on DNA stability and other health-related biochemical parameters: results of human intervention trials. Mol Nutr Food Res 60, 773-786.

8. Ross JA \& Kasum CM (2002) Dietary flavonoids: bioavailability, metabolic effects, and safety. Annu Rev Nutr 22, 19-34.
9. Kimata M, Shichijo M, Miura T et al. (2000) Effects of luteolin, quercetin and baicalein on immunoglobulin E-mediated mediator release from human cultured mast cells. Clin Exp Allergy 30, 501-508.

10. Ferrandiz ML \& Alcaraz MJ (1991) Anti-inflammatory activity and inhibition of arachidonic acid metabolism by flavonoids. Agents Actions 32, 283-288.

11. Regal JF, Fraser DG, Weeks CE et al. (2000) Dietary phytoestrogens have anti-inflammatory activity in a guinea pig model of asthma. Proc Soc Exp Biol Med 223, 372-378.

12. Homma M, Minami M, Taniguchi $C$ et al. (2000) Inhibitory effects of lignans and flavonoids in saiboku-to, a herbal medicine for bronchial asthma, on the release of leukotrienes from human polymorphonuclear leukocytes. Planta Med 66, 88-91.

13. Rice-Evans CA, Miller NJ \& Paganga G (1997) Antioxidant properties of phenolic compounds. Trends Plant Sci 2, 152-159.

14. Lago JH, Toledo-Arruda AC, Mernak M et al. (2014) Structure-activity association of flavonoids in lung diseases. Molecules 19, 3570-3595.

15. Smith WL, DeWitt DL \& Garavito RM (2000) Cyclooxygenases: structural, cellular, and molecular biology. Annu Rev Biochem 69, 145-182.

16. Ribeiro D, Freitas M, Tome SM et al. (2014) Inhibition of LOX by flavonoids: a structure-activity relationship study. Eur J Med Chem 72, 137-145.

17. Prochazkova D, Bousova I \& Wilhelmova N (2011) Antioxidant and prooxidant properties of flavonoids. Fitoterapia 82, 513-523.

18. Santana FP, Pinheiro NM, Mernak MI et al. (2016) Evidences of herbal medicine-derived natural products effects in inflammatory lung diseases. Mediators Inflamm 2016, 2348968

19. Knekt P, Kumpulainen J, Jarvinen R et al. (2002) Flavonoid intake and risk of chronic diseases. Am J Clin Nutr 76, 560-568.

20. Garcia V, Arts IC, Sterne JA et al. (2005) Dietary intake of flavonoids and asthma in adults. Eur Respir J 26, 449-452.

21. de Marco R, Accordini S, Antonicelli L et al. (2010) The gene-environment interactions in respiratory diseases (GEIRD) project. Int Arch Allergy Immunol 152, 255-263.

22. de Marco R, Poli A, Ferrari M et al. (2002) The impact of climate and traffic-related $\mathrm{NO}_{2}$ on the prevalence of asthma and allergic rhinitis in Italy. Clin Exp Allergy 32, 1405-1412.

23. de Marco R, Verlato G, Zanolin E et al. (1994) Nonresponse bias in EC Respiratory Health Survey in Italy. Eur Respir J 7, 2139-2145.

24. American Thoracic Society (1995) Standardization of spirometry, 1994 update. Am J Respir Crit Care Med 152, $1107-1136$

25. Quanjer PH, Stanojevic S, Cole TJ et al. (2012) Multi-ethnic reference values for spirometry for the 3-95-yr age range: the global lung function 2012 equations. Eur Respir J 40, 1324-1343.

26. Chinn S, Burney P, Jarvis D et al. (1997) Variation in bronchial responsiveness in the European Community Respiratory Health Survey (ECRHS). Eur Respir J 10, 2495-2501.

27. European Academy of Allergology and Clinical Immunology (1993) Position paper: allergen standardization and skin tests. Allergy 48, 48-82.

28. Pisani P, Faggiano F, Krogh V et al. (1997) Relative validity and reproducibility of a food frequency dietary questionnaire for use in the Italian EPIC centres. Int J Epidemiol 26, Suppl. 1, S152-S160.

29. Pala V, Sieri S, Palli D et al. (2003) Diet in the Italian EPIC cohorts: presentation of data and methodological issues. Tumori 89, 594-607.

30. Salvini S (1997) A food composition database for epidemiological studies in Italy. Cancer Lett 114, 299-300. 
31. Bhagwat S, Gebhardt S, Haytowitz DB et al. (2013) USDA Database for the Flavonoid Content of Selected Foods, Release 3.1. Beltsville, MD: US Department of Agriculture, Agricultural Research Service, Beltsville Human Nutrition Research Center, Nutrient Data Laboratory.

32. Bhagwat S, Haytowitz D, Prior R et al. (2015) USDA Database for Proanthocyanidin Content of Selected Foods, Release 2. Beltsville, MD: US Department of Agriculture, Agricultural Research Service, Beltsville Human Nutrition Research Center, Nutrient Data Laboratory.

33. Harris JA \& Benedict FG (1918) A biometric study of human basal metabolism. Proc Natl Acad Sci U S A 4, 370-373.

34. Fredrix EW, Soeters PB, Deerenberg IM et al. (1990) Resting and sleeping energy expenditure in the elderly. Eur J Clin Nutr 44, 741-747.

35. Slattery ML, Jacobs DR Jr, Dyer A et al. (1995) Dietary antioxidants and plasma lipids: the CARDIA Study. $J \mathrm{Am}$ Coll Nutr 14, 635-642.

36. Rebuck AS \& Chapman KR (1987) Asthma: 1. Pathophysiologic features and evaluation of severity. CMAJ 136, 351-354.

37. Eifan AO \& Durham SR (2016) Pathogenesis of rhinitis. Clin Exp Allergy 46, 1139-1151.

38. Braman SS (2006) Chronic cough due to chronic bronchitis: ACCP evidence-based clinical practice guidelines. Chest $\mathbf{1 2 9}$, 1 Suppl., 104S-115S.

39. Huk I, Brovkovych V, Nanobash Vili J et al. (1998) Bioflavonoid quercetin scavenges superoxide and increases nitric oxide concentration in ischaemia-reperfusion injury: an experimental study. Br J Surg 85, 1080-1085.

40. van Acker SA, Tromp MN, Haenen GR et al. (1995) Flavonoids as scavengers of nitric oxide radical. Biochem Biophys Res Commun 214, 755-759.

41. Middleton E Jr \& Kandaswami C (1992) Effects of flavonoids on immune and inflammatory cell functions. Biochem Pharmacol 43, 1167-1179.

42. Tanaka $\mathrm{T} \&$ Takahashi R (2013) Flavonoids and asthma. Nutrients 5, 2128-2143.

43. Shaheen SO, Sterne JA, Thompson RL et al. (2001) Dietary antioxidants and asthma in adults: population-based casecontrol study. Am J Respir Crit Care Med 164, 1823-1828.
44. Garcia-Larsen V, Arthur R, Potts JF et al. (2017) Is fruit and vegetable intake associated with asthma or chronic rhinosinusitis in European adults? Results from the Global Allergy and Asthma Network of Excellence (GA(2)LEN) Survey. Clin Transl Allergy 7, 3.

45. Tabak C, Arts IC, Smit HA et al. (2001) Chronic obstructive pulmonary disease and intake of catechins, flavonols, and flavones: the MORGEN Study. Am J Respir Crit Care Med 164, 61-64.

46. Smith LJ, Kalhan R, Wise RA et al. (2015) Effect of a soy isoflavone supplement on lung function and clinical outcomes in patients with poorly controlled asthma: a randomized clinical trial. JAMA 313, 2033-2043.

47. Cuervo A, Hevia A, Lopez P et al. (2016) Phenolic compounds from red wine and coffee are associated with specific intestinal microorganisms in allergic subjects. Food Funct $\mathbf{7}$, 104-109.

48. Bime C, Wei CY, Holbrook J et al. (2012) Association of dietary soy genistein intake with lung function and asthma control: a post-hoc analysis of patients enrolled in a prospective multicentre clinical trial. Prim Care Respir J 21, 398-404.

49. Watson RR, Zibadi S, Rafatpanah $\mathrm{H}$ et al. (2008) Oral administration of the purple passion fruit peel extract reduces wheeze and cough and improves shortness of breath in adults with asthma. Nutr Res 28, 166-171.

50. Hamizan AW, Rimmer J, Alvarado R et al. (2017) Positive allergen reaction in allergic and nonallergic rhinitis: a systematic review. Int Forum Allergy Rhinol 7, 868-877.

51. Ross SM (2016) Allergic rhinitis: a proprietary extract of Pinus pinaster Aiton (pycnogenol) is found to improve the symptoms associated with allergic rhinitis. Holist Nurs Pract 30, 301-304.

52. Hirano T, Kawai M, Arimitsu J et al. (2009) Preventative effect of a flavonoid, enzymatically modified isoquercitrin on ocular symptoms of Japanese cedar pollinosis. Allergol Int 58, 373-382.

53. Macdonald HM, New SA \& Reid DM (2005) Longitudinal changes in dietary intake in Scottish women around the menopause: changes in dietary pattern result in minor changes in nutrient intake. Public Health Nutr 8, 409-416. 